\title{
Subjectivity Bias elimination in employee appraisal process: Role of people analytics
}

\author{
D. Saha* \\ Symbiosis Institute of Business Management, Pune, India
}

DOI: http://doi.org/10.52814/PJMA.2021.1111

ARTICLE TYPE: Review paper

ARTICLE HISTORY: Submitted: January 2021, Revisions: March 2021, Accepted: March 2021

HOW TO CITE: Saha, D. (2021). Subjectivity Bias elimination in employee appraisal process: Role of people analytics. Prayukti - Journal of Management Applications, Vol. 1, Issue 1, pp. 76-81.

*Corresponding author e-mail: iamdebadrito@gmail.com

\begin{abstract}
Human Resource, being an important strategic part in any organization is continuously moving towards data-driven processes and this research paper reveals how maturity in Data Analytics in Appraisal process can be a game changer in any organization and helps in increasing organizational effectiveness by proper judgmental techniques. Although Organizations around the globe recently started to utilize Analytics extensively in different Human Resource functionalities, still there is no extensive research on how it can be utilized in Performance Appraisal procedure, being a central part of Human Resource Management and organizations are way far behind in implementing Human Resource Analytics in Performance Management system. This research paper, an interdisciplinary study of Social Psychology and Information Technology, serves the purpose of dealing with different types of Human Subjective Biases which are prevalent in the organizations and leads to erroneous subjective judgments based on instinct; the transformation journey from HRIS to HR metrics and then to HR Analytics; types of Workforce Analytics and finally how Human Resource Analytics can help the Human Resource practitioners in objective decision making based on evidence rather than intuition at the time of Performance Appraisal. Knowledge acquiring from this research can equip the researchers, academicians and Human Resource practitioners to gain insight about implementation of HR Analytics in Performance Appraisal and further research on this emerging topic.
\end{abstract}

KEYWORDS: Human Resource Analytics, Appraisal Process, Performance Management, Human Subjective Bias, Subjective Judgment, Objective Decision Making.

\section{INTRODUCTION}

The improvement of the efficiency and performance of an employee is closely tied with the performance evaluations during the Performance Appraisal process (Latham and Mann, 2006). An inaccurate Performance Appraisal accounts for the discontentment of the 
employees which is why there is a high attrition rate just after the yearly appraisal comes out. A biased Performance Appraisal process creates a hindrance for evidence based ethical decision-making process which accounts for the dissatisfaction of the employees, which in turn accounts for employee outcomes in a negative way like lower commitment levels and higher turnover ratio (Idowu, 2017). A biased Performance Appraisal system impacts an organization as well as its employees negatively because it leads to the progression of an employee over others in an unfair manner (Brown et.al., 2010), and thus limits the organization's capability to nurture its top talents and implementation of succession planning (Sharma et. al., 2003). The cognitive ability of the managers to recall an employee's performance over a period of time accounts for an inaccurate Performance Appraisal as it leads to observational inaccuracy (Sharma and Sharma, 2017) and reduction of the lifetime value of an employee (Bell and Arthur, 2008) which ultimately results in the ineffectiveness of the Performance Appraisal system. Different types of Biases are very much prevalent during the time of Performance Appraisal. All the biases are bad - this is a misconception because many of them help to make decisions in a quick and time-saving manner (Donaldson and Grant-Vallone, 2002). But many a time, harmful human biases account for unconscious errors in the process of collection of the data and when the distorted data is used in the appraisal process, it hampers the process of performance management and optimization of the collaboration among the employees (Gudmundsson and Lechner, 2003).

\section{PRESENCE OF SUBJECTIVITY BIAS IN PERFORMANCE APPRAISAL SYSTEM}

- Strictness Bias: Strictness Bias accounts for attributing low ratings in every parameter of an appraisal (DeNisi and Pritchard, 2006), which eventually accounts for a by and large negative impression of a particular employee (Kromrei, 2015) and serious implications in HR decision making.

- Leniency Bias: Leniency Bias leads to providing high inflated ratings in all the parameters of an appraisal, which creates a pseudo positive sense of an employee (McGregor, 1987).

- In-Group Bias: In-Group Bias is a partiality of considering the staff of own team as more proficient than staff not of a particular team (Brewer, 1979).

- Central Tendncy Bias: Central Tendency Bias is the main cause of a normally distributed and bell-shaped overall performance curve. It is related to scoring each of the questions on a scale near the center or average (Deshmukh and Patel, 2019).

- Horn Effect: Horn effect denotes the tendency where the assessors mark everything on the low end of performance scale because of a single negative parameter considered (Sundar et al, 2014).

- Selective Perception: Managers selectively construe what they see depending upon individual attitudes, interests, and experience in Selective Perception or 'Similar to me bias' which leads to an erroneous assessment of an employee (Dusterhoff et al., 2014).

- Halo Effect: Halo Effect leads to drawing an impression by and large about an individual on the basis of a single characteristic (Coombs and Holladay, 2006).

- Contrast Effect: Contrast Effect denotes the evaluations of an employee's characteristics that are either underestimated or exaggerated by the comparisons with other employees of late encountered who rank higher or lower on the similar characteristics (Palmer and Gore, 2014).

- Projection: Projection denotes attributing evaluator's own characteristics to the employees whom he or she evaluates (Bazinger and Kühberger, 2012). Same religions, same gender, same political preference etc are part of projection which accounts for subjective judgement (Kaifi and Noori, 2011). 
- Stereotyping: Stereotyping is associated with evaluating an employee on the basis of the evaluator's perception of the team to which the particular employee belongs to (Walton et al, 2014).

- Spillover Effect: Spillover Effect is the resultant effect of an employee's performance in the previous appraisal cycle. A well performance in the preceding appraisal cycle accounts for an artificially elevated rating even if the performance is average in the present appraisal cycle (Nilsson et al, 2017). The opposite incident is also factual in performance appraisal system where the negative performance of previous year can misconstrue a good performance in the present appraisal cycle (Wood et al, 2013).

\section{OPEN BOX PERFORMANCE APPRAISAL SYSTEM AND HOW IT LEADS TO SUBJECTIVITY BIAS}

Open Box Performance Appraisal System, the most used Performance Appraisal System in different organizations till now, is open to prejudiced parameters (Saffie-Robertson and Brutus, 2014) as it mainly depends on the qualitative techniques instead of the quantitative ones (Hasan and Huq, 2010). In the Open Box Performance Management System, the evaluators have to answer ambiguous open-ended questions about their employees descriptively in a blank space or open box which leads to subjective judgment and evaluation discrepancy. There is a high chance of Subjectivity Bias in Performance Appraisal when the criteria and the contexts for evaluations are indistinct and depending on gut feeling (Javidmehr and Ebrahimpour, 2015) and thus it accounts for the Idiosyncratic-Rater Effect (Paramesh et al, 2020) where assessment and rating is variable and depending upon managers and other evaluators (Van der Heijden and Nijhof, 2004). The assessors tend to rely on socalled stereotypes such as gender, race, and ethnicity at the time of making decisions (Jacobs et al., 2014) in the absence of an Objective Performance Management System (Mackenzie et al 2019). But it is to be mentioned that it is not always possible to eliminate the subjectivity factors in a Performance Appraisal system because taking into account some of the subjectivity factors (Fedor et al., 2001) which capture some crucial parameters that an assessor cannot capture through a purely objective and quantifiable Appraisal process (Keeping and Levy, 2000).

\section{HRIS TO HR ANALYTICS}

Introduction of the Human Resource Information System (HRIS) radically transformed different functionalities of the Human Resource management. Then an advent of analytics - HR Analytics further transforms the Human Resource functionalities. People Analytics consists of six types of analytical practices as per Harris et al. (2011) for analysis of data related to Human Resource practices. HR Analytics is an IT warranted process of managing workforce for visualization and statistical analyses of data of Human Resource (Marler and Boudreau, 2017), which have a significant influence on business and ultimately enables in decision making process backed by data. Falletta (2014) considered 18 Human Resource practices correlated to HR Analytics and Bassi (2011) described People Analytics as analytics enabled by evidence which results in better decision making on the business workforce. Rasmussen and Ulrich mentioned People Analytics about an activism and change management (Rasmussen \& Ulrich, 2015), and not only about scientific research. Church et al. (2015) defined Human Resource Analytics as an information management helping in organizational decision making related to its workforce by various qualitative and quantitative parameters. HR Analytics can be subdivided into Organizational Culture Analytics, Leadership Analytics, Employee Churn Analytics and Capacity Analytics.

\section{ORGANIZATIONAL CULTURE ANALYTICS}

Rules and regulations - either spoken or unspoken, work patterns and most importantly the work culture plays a fundamental role in the Performance Appraisal Process. 
Organizational Culture Analytics helps to identify the patterns of different biases associated with the Organizational culture (Corritore et al, 2020) and thus helps to eliminate the same.

\section{LEADERSHIP ANALYTICS}

The leaders of an organization motivate the existing workforce for better performance and the Leadership Analytics is majorly applied in employee retention and appraisal of the leaders (Tsai et al, 2019), which requires prudence in every organization because these positions are not easy to replace.

\section{EMPLOYEE CHURN ANALYTICS}

The thrust area of Employee Churn Analytics is the assessment of the workforce and estimates Employee Turnover Ratio (Yi git and Shourabizadeh, 2017) with the help of historical data of the Turnover Rate and previous performance to eliminate Subjectivity Bias from Performance Appraisal System.

\section{CAPACITY ANALYTICS}

The focused area of the Capacity Analytics involves behavioral analytics that seeks to determine the capacity of an individual employee's growth and incorporation of that in the Performance Appraisal System (Chen and Huang, 2009).

Incorporation of Analytics into the procedure of Performance Appraisal is beneficial to organizations as well as employees because the employees' perception about the Performance Appraisal process heavily depends upon the fairness and accurateness of the Performance Appraisal Process (Bose, 2015). HR Analytics helps to make the appraisal process fairer by elimination of different types of biases. The presence of the subjective elements in the HR-Score Card accounts for uncertainty in the reward system (Becker et al, 2001) and thus quid pro quo and favoritism play a central role instead of actual parameters for performance evaluation as per the principal agent model (Kremer, 2018). This favoritism can be eliminated by objective evaluation criteria and objective performance measurement (Hanada and Garima, 2014).

Different Analytics Software like IBM Kenexa powered by IBM Watson, Visier, CPLEX Optimizer, Qlik, Synergita help for the perfection of the Performance Appraisal process by eliminating subjectivity bias which in turn helps in optimization of Talent Management (Kaur and Fink, 2018).

\section{HOW HR ANALYTICS IMPROVES PERFORMANCE APPRAISAL}

How much HR analytics is able to diminish Subjectivity Bias in the Performance Appraisal Process is very much dependent upon how superior or inferior the data is because the concept of "Garbage In Garbage Out" is very much prevalent in HR Analytics (Stone et al., 2015). Organizations collect data through various information systems along with HRIS powered by the advent of Information Technology. But these are of little use, if there is an inappropriate analysis of data (Pape, 2016). So, the agenda of data-oriented leadership should be to collect and analyze the data which is important rather than what data is easy to capture (LaValle et al., 2011) and it is extremely important to have a data-driven culture for decision making (Chong and Shi, 2015).

HR Analytics in Performance Appraisal gathers enormous importance after 2020 when the pandemic disrupted the world. As a result of this pandemic, the need for the gig workers increases manifolds, and work from home becomes the new norm. As the chance of face-to-face discussion and meeting becomes less, so the chance of physical supervision of subordinates by managers is not easy which culminates into distorted and discriminatory Appraisal depending upon inaccurate and subjective judgments of the managers. Here comes the importance of HR Analytics. Employees' performance analysis and career-alignment can be mapped with the help of HR Analytics and thus it helps the employers to find the right fit for a particular job and keeps them more engaged by satisfying the goal of Employee Engagement (Karmańska, 2020). Its functionalities are superior to the HR Metrics as well as 
the HR Balanced Scorecards (Hagood and Friedman, 2002) in the virtual work environment because it not only helps in quick decision making backed up by data but also helps in strategic decision making by Predictive Analytics backed by evidence. Predictive Analytics being proactive helps to determine the employee engagement level, cultural fitment, capability of up-skilling and re-skilling which in turn makes the Performance Appraisal Process more objective as well as robust. Along with these, Multivariate Models, Preparation of information and Root Cause Analysis (RCA) (Levenson, 2013), Turnover Modeling, Response Modeling, Risk Modeling, Talent Forecasting help to improve Performance Management in organizations. Thus, it helps in deriving better Decision Making by the elimination of Subjectivity Bias caused by human cognition..

HR Analytics being reactive helps the managers to leverage real-time data analytics for identifying the performance curve of an employee (Ben-Gal, 2019). Thus, it helps in providing immediate feedback which helps in the improvement of employee morale in the short term and development of his/her career in the long term and thus accentuate the insights of the business from data analytics.

\section{CONCLUSION}

None contradicts that fair Compensation Management and Performance Appraisal system are extremely important in any organization because it helps to align individual's performance with the objectives of the organization. Performance management, if not done carefully and accurately, can have a severe adverse impression on the enthusiasm level of the good performers. If the good performance of an employee is not acknowledged by his/her organization, his/her performance can plummet significantly. If the Performance Appraisal process does not help to differentiate a good performance from an ordinary performance, then the good performer does not garner motivation to perform well again. On the contrary, if the Performance Appraisal process is the true reflection of the knowledge, skill, and abilities of the workforce; then the employees of the organization accept the Performance Appraisal System in a fair manner. Additionally, it creates a value addition for the supervisor because he/she would not need to find an alternative way for performance improvement of the employees because the workforce is more likely to admit the feedback provided by the supervisor.

So, Performance Appraisal System must have more objective and quantifiable criteria instead of subjective ones and HR Analytics helps to reach that goal of objectivity. HR Analytics, consisting of various modeling tools such as ROI Analytics, Cost-benefit Analytics, Behavioral modeling, helps in unbiased decision-making in the Performance Appraisal System. As per a study by Deloitte Research in 2020, $92 \%$ of the organizations which incorporates HR Analytics in Performance Management System, find an improvement in Employee Engagement. The study also shows that $83 \%$ of the same cohorts of organizations are able to implement better MBO (Management by Objective) with the help of HR Analytics. Thus, HR Analytics proves its mettle to capture comprehensive crossfunctional data and hence helps the Human Resource Managers to gain insights about the fact-based decisions strategically instead of intuitions.

\section{REFERENCES}

- Bassi, L. (2011). Raging debates in HR Analytics. People \& Strategy, Vol. 34, pp. 14-18.

- Bazinger, C., Kühberger, A. (2012). Is social projection based on simulation or theory? Why new methods areneeded for differentiating. New Ideas in Psychology, 30(3), 328-335.

- Becker, B. E., Huselid, M. A., Huselid, M. A., \& Ulrich, D. (2001). The HR scorecard: Linking people, strategy, and performance. Harvard Business Press.

- Bell, S. T., \& Arthur Jr, W. (2008). Feedback acceptance in developmental assessment centers: The role of feedback message, participant personality, and affective response to the feedback session. Journal of Organizational Behavior: The 
International Journal of Industrial, Occupational and Organizational Psychology and Behavior, 29(5), 681-703.

- Bose, M. T. (2015). Growing impact of human capital analytics on modern economy: a generic overview. Journal of Business and Management, 17(1), 11-13.

- Brewer, M. B. (1979). In-group bias in the minimal intergroup situation: A cognitivemotivational analysis. Psychological bulletin, 86(2), 307.

- Brown, M., Hyatt, D., \& Benson, J. (2010). Consequences of the performance appraisal experience. Personnel review.

- Chen, C. J., \& Huang, J. W. (2009). Strategic human resource practices and innovation performance-The mediating role of knowledge management capacity. Journal of business research, 62(1), 104-114.

- Chong, D., \& Shi, H. (2015). Big data analytics: a literature review. Journal of Management Analytics, 2(3), 175-201.

- Church, A. H., Ginther, N. M., Levine, R., \& Rotolo, C. T. (2015). Going beyond the fix: Taking performance management to the next level. Industrial and Organizational Psychology, 8(1), 121-129.

- Coombs, W. T., \& Holladay, S. J. (2006). Unpacking the halo effect: Reputation and crisis management. Journal of Communication Management.

- Corritore, M., Goldberg, A., \& Srivastava, S. B. (2020). The new analytics of culture. Harvard Business Review, 98(1), 76-83.

- Deshmukh, D., \& Patel, J. (2019). Research Paper on Bell Curve Method of Performance Management. International Journal of Management, 10(1).

- Kumar, A. and Vinaydeep (2012). "Intrinsic Reward System \& Motivation: A Study of Management Teachers Perspective". International Journal of Human Resource Management and Research, Vol. 2, Issue 4: December, pp. 33-44.

- Navya, V. and Aswathy, P. V. (2019). "A Study on the Impact of Employee Motivation on Employee Performance with Special Reference to Wheels India Limited". MERC Global's International Journal of Management, Vol. 7, Issue 2, pp. 120-126.

- Sahoo, Chandrakanta and Sahoo, Deepak Kumar (2018). "Antecedents and Outcomes of Employee Experience in BSNL". MERC Global's International Journal of Management, Vol. 6, Issue 4, pp. 118-126.

- Yadav, Archana (2020). "Employee Retention and Employee Engagement". MERC Global's International Journal of Management, Vol. 8, Issue 2, pp. 47-52. 